\title{
The Relationship between Knowledge Management and Trust: Malaysian Perspective
}

\author{
Rohana Ngah (corresponding author) \\ Universiti Malaya, Malaysia. \\ Tel: 6016-2065756_Email: hana_ngah@perdana.um.edu.my \\ Chua Hock Hoo \\ Universiti Malaya, Malaysia. \\ Tel: 603-78948988Ｅmail: hhchua@chengco.com.my
}

\author{
Abdul Razak Ibrahim \\ Universiti Malaya, Malaysia. \\ Tel: 603-79673989_Email: razak@um.edu.my
}

\begin{abstract}
In delivering a professional service to its clients, knowledge is an auditing firm's core capital. In conducting its practice and business, an auditing firm not only captures knowledge within its organization from among its own people but also from its clients to whom it has a responsibility and duty to protect. The nature of auditing firms somehow controls the flow of knowledge in the firms. Knowledge management is crucial, especially for knowledge-intensive firms that utilize and capitalize knowledge in all their transactions. The challenges are to highlight the knowledge management factors in auditing firms and how much knowledge management contributes to their organizational effectiveness. This empirical study reveals that knowledge dissemination, knowledge storing and knowledge protection are more prominent in this type of industry. In addition, trust plays a very crucial role in knowledge flow. Knowledge dissemination was found to be a main contributor towards organizational effectiveness and trust prevails as an important factor in knowledge management applications in the industry.
\end{abstract}

Keywords: Knowledge Management, Trust, Auditing Firms, Malaysia 


\section{Introduction}

The resource and knowledge based views of the firm have prompted strategy researchers to focus on value creation, as opposed to value appropriation (Conner and Prahalad, 1996; Kogut and Zander, 1996; Nahapiet and Ghosal, 1998). Strategy and entrepreneurship research shares an interest in resource acquisition, sharing, and exploitation for the purpose of value creation (Yli-Renko et al, 2001). Of the various resources available to the firm, knowledge is arguably the most important (Spender, 1996). By highlighting the important links of knowledge management, trust and organizational effectiveness in auditing firms, this research will contribute a further convergence between the domains of knowledge management and entrepreneurship research.

Knowledge lies in human minds and exists only if there is a human mind to do the knowing (Widen-Wulff and Suomi, 2007). There are three dimensions of knowledge: width, depth and tacitness (Nooteboom, 1993). Knowledge can be created by intentional and resource-consuming efforts ( $\mathrm{Du}$ et al, 2007). The neglect of tacit knowledge, based on people and ideas, has undoubtedly reduced the corporate market place's capability for true innovation and sustainable competitiveness (Gamble and Blackwell, 2001). According to Alavi and Leidner (2001), knowledge management is largely regarded as a process involving various activities and a minimum of four basic processes must exist - creating, storing/retrieving, transferring and applying knowledge. Knowledge management is about managing the knowledge that an individual possesses.

In a commercial environment, knowledge must be put to work in three primary areas; customer needs, concern processes and body of knowledge (Gamble and Blackwell, 2000). Every member of an organization must understand how his or her work contributes to fulfilling customer needs and how the products and services of the enterprise provide customer value. Then members of the organization must understand how his or her work relates to the work of others. The last part of the process is the flow of knowledge that, to varying degrees, every person must understand something about the subject matter with which members of the organization deal. This requires a deeper knowledge of relationships and meanings, both within the enterprise and the outside world. Therefore, a business idea is considered successful when it delivers value and profit. Knowledge must be continuously flowing in the organization. As long as there is a stock of knowledge, during any period of time, a flow of knowledge should take place (Stewart, 2000). Making knowledge available to others and capturing new knowledge as well has been described by Nonaka (1991) as the spiral of knowledge. Nonaka and Takeuchi (1995) examine the concept in terms of a knowledge spiral encompassing four basic patterns of interaction between tacit and explicit knowledge: socialization, externalization, combination and internalization. The flow of knowledge from an individual to another resulted in collective effort in completing their audit projects, thus, enhancing organizational effectiveness. This knowledge spiral consists of knowledge acquisition, conversion, application, storage, dissemination and protection. Auditing firms have two challenges in managing their knowledge: the changing nature of knowledge and information services required by their clients and the changing nature of knowledge and information required to satisfy their knowledge employees (Taylor et al, 
2001). Knowledge intensive firms, like auditing firms, cited knowledge as their core capital for their business (Dunford, 2000).

"Knowledge capital is our most valuable asset and it drives our organization. It's what we sell” (George Shaheen, Managing Partner/CEO, Andersen Consulting, 1998, p. 1) (Dunford, 2000).

"Knowledge is the lifeblood of McKinsey (Rajat Gupta, Managing Director, McKinsey and Company, quoted in Bartlett, 1998, p.1)

Knowledge intensive firms that depend on knowledge capital consider knowledge management to be a core capability for achieving competitive advantage (Chard, 1997; Pasternack and Viscio, 1998). Large and established auditing firms like Andersen, and Ernst and Young spend about six percent of their revenue on knowledge management (Davenport and Prusak, 1998). These large auditing firms have created a system to ensure the success of knowledge management in their firms. KPMT has developed a knowledge management process comprising six stages:

1. acquisition (collecting, synthesizing and interpreting information from diverse sources from external and internal sources)

2. indexing (development of classification schemes)

3. filtering (screening information for its importance)

4. linking (connecting related information)

5. distribution; and

6. application.

However, while expectation is high, many knowledge management projects failed (Davenport et al, 1998) and knowledge management remains a major challenge to consulting firms (Durfort, 2000). Fahey and Prusak (Dunfort, 2000) listed the eleven deadliest sins of knowledge management as shown below:

Table 1: Deadliest sins of knowledge management

\begin{tabular}{|l|l|}
\hline Error & Description \\
\hline 1 & Not developing a working definition of knowledge \\
\hline 2 & Emphasizing knowledge stock to the detriment of knowledge flow \\
\hline 3 & Viewing knowledge as existing predominantly outside the heads of individuals \\
\hline 4 & $\begin{array}{l}\text { Not understanding that a fundamental intermediate purpose of managing } \\
\text { knowledge is to create shared context }\end{array}$ \\
\hline 5 & Paying little heed to the role and importance of tacit knowledge \\
\hline 6 & Disentangling knowledge from its uses \\
\hline 7 & Downplaying thinking and reasoning \\
\hline 8 & Focusing on the past and the present and not the future \\
\hline
\end{tabular}




\begin{tabular}{|l|l|}
\hline 9 & Failing to recognize the importance of experimentation \\
\hline 10 & Substituting technological contact for human interface \\
\hline 11 & Seeking to develop direct measures of knowledge \\
\hline
\end{tabular}

In auditing firms, the employees share common knowledge that is known to all members of the organization (Desouza and Awazu, 2006). When knowledge is considered an asset for individuals, trust plays a major role in knowledge management activities. "The greater the level of trust within a company, the greater the likelihood of cooperation. And cooperation itself breeds trust" (Putnam, 1993, p.171). According to De Tienne et al (2004), transformation of knowledge occurs when individuals communicate and interact in order to synthesize their individual knowledge, then distribution occurs when agreed-upon knowledge and competencies are used repeatedly and subsequently embodied in the organization's norms and values or culture. Finally integration occurs when the organization successfully captures external knowledge and successfully integrates it with internal knowledge (De Tienne, 2004). According to Snowden (2000) trust is the most critical prerequisite for knowledge exchange. This is supported by Davenport and Prusak (1998) who posit that without trust, knowledge initiates will fail, regardless of how thoroughly they are supported by technology or rhetoric. For a knowledge market to operate in an organization, trust must be established in the following three ways:

1. Trust must be visible. The members of the organization must see people get credit for knowledge sharing. There is a direct evidence of trust.

2. Trust must be ubiquitous. The internal knowledge market must be trustworthy or else the market will be less efficient.

3. Trustworthiness must start at the top. Trust tends to flow downward through organizations. Trust value in the organization is identified through signals, signs and symbols. (Davenport and Prusak, 1998).

Levin and Cross (2004) discovered that trust has a strong moderating effect in the relationship of tie strength and knowledge usage. Without trust, the tie strength would be weak ties to knowledge usage. Developing trust among employees is crucial in ensuring organizational knowledge development, which is critical for continuous innovation (Chowdhury, 2005).

This paper is organized into four sections: Section 1 will discuss knowledge management and organizational effectiveness. Section 2 will discuss the research design. Section 3 is the findings and Section 4 is the conclusion.

\section{Research Design and Methodology}

\subsection{Hypothesis Development}

This paper examines knowledge management in two ways. The first is to examine the knowledge management factors of auditing firms to organizational effectiveness. In small 
firms, knowledge is gained through experience and the associated tacit and explicit learning of an individual (Thorpe et al, 2005). Auditing firms are rich in knowledge, be it from its clients, suppliers or from its professional staff, particularly auditors. Nunes et al (2006) point out that knowledge acquisition, storing, application and sharing processes should be regarded as crucial and core by knowledge intensive firms, especially consulting firms. Knowledge management can be described along two dimensions: knowledge sharing and the capability to create, store, share and use an organization's explicitly documented knowledge (Lee 7 Choi, 2003). Based on Darroch (2005) and Gold et al (2001) research, knowledge application, dissemination and knowledge protection represents significant factors of knowledge management in auditing firms. Knowledge is a stock of expertise (Baunmard, 2002), therefore, it needs to be disseminated in the organization to make it valuable for the organization.

H1: Knowledge management positively affects organizational effectiveness

The second way is to examine the knowledge management factors of organizational effectiveness with the presence of trust. The advantage of smaller firms is the close networking among their employees. This helps the cultivation of trust among employees. Yli-Renko et al (2001) stress that trust enhances knowledge acquisition by improving access to the external sources of knowledge, by increasing the willingness and ability of exchange partners to identify exchange and assimilate knowledge, and by improving the breadth and efficiency of knowledge transfer. However, Politis (2003) argues that trust should exist prior to knowledge acquisition in improving team performance. Trust, either benevolence or competence based, improves the usefulness of tacit and explicit knowledge exchange or knowledge management (Levin and Cross, 2004). Trust as social capital can be a factor in determining organizational capacity for knowledge management (Hoffman et al, 2005).

$\mathrm{H} 2$ : Trust influences the affect of knowledge management on organizational effectiveness

Based on the literature review and hypotheses developed, a framework - to guide the study was developed as shown in Figure 1.

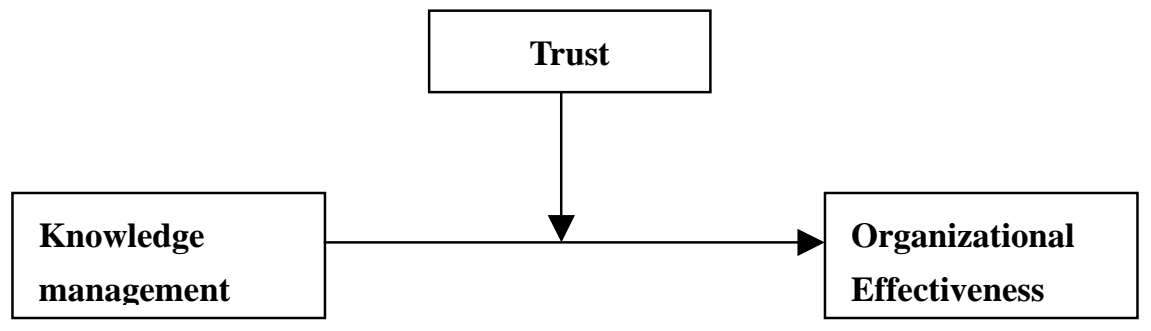

Figure 1: Proposed Model

\subsection{Data and Measures}

The aim of this study is to evaluate the effects of knowledge management on organizational effectiveness. Knowledge management was measured using items from Gold et al (2003), Chang et al (2005), Darroch (2004) and Egbu et al (2005). Trust was measured using items 
from Yli-Renko et al (2001), Nahapiet and Ghosal (1998) and Lee and Choi (2003). Organizational effectiveness was measured using items from Gold et al (2003) and Cameron and Quinn (1999). All items were measured on a seven point Likert-type scale where $1=$ strongly disagree and $7=$ strongly agree.

The sample was drawn from auditing firms in Malaysia. The list of auditing firms was obtained from the Malaysian Institute of Accountants, which is the statutory body to administer auditing firms in Malaysia. A total of 500 questionnaires were distributed by mail. Two weeks after distribution, a phone call was made as a reminder. Only 232 questionnaires were useable indicating a $42 \%$ response rate, which is considered an effective response rate.

Most of the respondents are female, contributing $68 \%$ of total respondents. Auditors and tax executives represent $41 \%$ followed by managers (30\%), administrative personnel $(20 \%)$ and partners, including senior partners, $(8 \%)$. A total of $78 \%$ of the respondents are from auditing firms that have been operating for more than 10 years. Most of the respondents are from auditing firms that have more than three partners (36\%), which is followed by auditing firms of two partners (32\%). Most of the participating firms have more than 20 employees $(51 \%)$.

\section{Results and Discussion}

The reliability test was carried out to determine the reliability of the questions. Reliability analysis provides information about the relationships between individual items in a scale. When a previously validated instrument has been adopted, a higher cut-off value of 0.7 or higher may be used (Nunnaly, 1978). Since all the Cronbach's Alpha values are over the critical point of 0.7 the survey's reliability is accepted.

Table 2: Reliability Test

\begin{tabular}{|l|l|l|}
\hline Variable & Items & $\begin{array}{l}\text { Cronbach's } \\
\text { Alpha }\end{array}$ \\
\hline $\begin{array}{l}\text { Knowledge } \\
\text { Acquisition }\end{array}$ & 15 & 0.919 \\
\hline $\begin{array}{l}\text { Knowledge } \\
\text { Conversion }\end{array}$ & 10 & 0.935 \\
\hline $\begin{array}{l}\text { Knowledge } \\
\text { Application }\end{array}$ & 17 & 0.962 \\
\hline $\begin{array}{l}\text { Knowledge Storing } \\
\text { Knowledge } \\
\text { Dissemination }\end{array}$ & 16 & 0.919 \\
\hline Knowledge & 10 & 0.942 \\
\hline
\end{tabular}




\begin{tabular}{|l|l|l|}
\hline Protection & 11 & 0.959 \\
\hline Trust & 16 & 0.964 \\
\hline $\begin{array}{l}\text { Organizational } \\
\text { Effectiveness }\end{array}$ & 16 & \\
\hline
\end{tabular}

The result reveals strong correlations in all knowledge management factors and organizational effectiveness. The correlation data is shown below in Table 3 .

Table 3: Correlation of Knowledge Management dimensions and Organizational Effectiveness

\begin{tabular}{|l|l|l|}
\hline \multicolumn{2}{|l|}{} & $\begin{array}{l}\text { Organizational } \\
\text { Effectiveness }\end{array}$ \\
\hline $\begin{array}{l}\text { Pearson } \\
\text { Correlation }\end{array}$ & $\begin{array}{l}\text { Knowledge } \\
\text { Acquisition }\end{array}$ & 0.650 \\
\hline & $\begin{array}{l}\text { Knowledge } \\
\text { Conversion }\end{array}$ & 0.574 \\
\hline & $\begin{array}{l}\text { Knowledge } \\
\text { Application }\end{array}$ & 0.697 \\
\hline & $\begin{array}{l}\text { Knowledge } \\
\text { Storing }\end{array}$ & 0.675 \\
\hline & $\begin{array}{l}\text { Knowledge } \\
\text { Dissemination }\end{array}$ & 0.742 \\
\hline & $\begin{array}{l}\text { Knowledge } \\
\text { Protection }\end{array}$ & 0.681 \\
\hline
\end{tabular}

Gold et al (2001) found that the knowledge management process capability of knowledge acquisition, conversion; application and protection has a strong magnitude towards each other.

Hypothesis H1 examines the effects of knowledge management on organizational effectiveness. To investigate this relationship, the knowledge management factors are entered in a single block. There is a positive relationship between knowledge management and organizational effectiveness. The proposed model is significant $(F=71.589 ; p<0.00)$; it explains $65 \%$ of variance in organizational effectiveness. The knowledge acquisition, dissemination and protection are found to be essential for organizational effectiveness, especially knowledge application, which has a significant positive influence on organizational effectiveness $(\beta=0.428, \mathrm{t}$ value $=4.847, \mathrm{p}<0.00)$. The strong relationship between knowledge management and organizational effectiveness is supported by Gold et al (2001), Lee and Sukoco (2007) and Lee and Choi (2003). This finding is also supported by Darroch (2005) who found that knowledge acquisition, knowledge dissemination and 
responsiveness to knowledge positively affect firm performance and innovation. In this study, knowledge application, conversion and storing do not significantly affect organizational effectiveness, which is in contrast to Nunes et al (2005) who highlighted the importance of knowledge storing and application to consulting firms. The collinearity statistic of B showed a value which is not close to 0 , which means there is no multicolinearity among the factors. Therefore $\mathrm{H} 1$ is supported.

Hypothesis $\mathrm{H} 2$ investigates the role of trust as our moderating variable; regression analysis showed that with trust, the model is significant as a whole $(\mathrm{F}=71.953 ; \mathrm{p}<0.00)$; it explains $69 \%$ of variance in organizational effectiveness, which is better than the first model. Therefore, trust improves the relationship of knowledge management and organizational effectiveness. Hence, the $\mathrm{H} 2$ hypothesis, that trust improves the relationship of organizational effectiveness is supported.

Whether knowledge management is being practiced in the organization $-83 \%$ of respondents agreed that knowledge management is practiced in their firms, $11 \%$ disagree and 5\% did not know whether knowledge management is practiced in their firms. Out of that population, $10 \%$ of auditors did not know whether knowledge management exists in their firms while another $10 \%$ did not know what knowledge management was. This could be true as Desouza and Awazu (2006) in their study found that SME, knowingly or unknowingly, manage knowledge and that while some have mechanisms for knowledge management others conduct it on the periphery.

\section{Conclusion}

The positive relationship between knowledge application, knowledge dissemination and knowledge protection is supported by the findings of Gold et al (2003), on large finance and manufacturing firms with sales profits of over USD100 million. Large auditing firms have a greater advantage in developing extensive knowledge management systems compared to small auditing firms. This result is also supported by Darroch (2004) who found a positive relationship between knowledge management and organizational effectiveness, particularly knowledge dissemination. Knowledge protection is very important in the auditing industry, however, in this study; knowledge dissemination is more significant in the industry. This is due to the auditing firm environment where auditors have to share their knowledge as they are working in a team. However, auditing firms are still lacking in knowledge acquisition, knowledge creation and knowledge storing. Knowledge management requires a major shift and commitment of everyone in the organization in adopting each factor of knowledge management to make it work (Gupta et al, 2000). Working together as a team on various projects develops a good culture and commitment among auditors, which encourages knowledge application and dissemination. Knowledge is a stock of expertise (Baunmard, 2002), therefore, it needs to be disseminated in the organization to make it valuable for the organization. Trust is important in network relationships for firms to create and disseminate knowledge (Gold et al, 2001). In this study, trust moderates the effect of knowledge management and organizational effectiveness, which proves that trust is very important for knowledge flow within an organization (Yli-Renko et al, 2007). This is definitely true in 
auditing firms where all knowledge and information is considered confidential and classified. Furthermore, it is the nature of auditing firms to be careful and discreet in handling their information, especially that of their clients. The setting of auditing firms emphasizes the importance of knowledge protection and trust, which further strengthens the network relationships internally, and, consequently, enhances organizational effectiveness. Trust makes the knowledge management process more efficient (Hoffman et al, 2005). This study has given some insights into knowledge management practice in auditing firms, especially in Malaysia. Unlike large auditing firms like Andersen, and Ernst and Young (Davenport and Prusak, 1998), which allocate a large budget and a lot of effort to develop their knowledge management system, knowledge management is considered to be still in its infancy in Malaysia (Tat \& Hase, 2007). According to Hansen et al (1999), the consulting business normally employs two very different knowledge management strategies, codification and personalization. In a codification strategy, knowledge is carefully codified and stored in databases that focus on computers, whereas in a personalization strategy, knowledge is closely tied to the person who developed it and is shared mainly through direct person-to-person contact. Auditing firms in Malaysia are more in line with the personalization strategy, where only certain parts of knowledge management are practiced. However, ignorance in knowledge storing might be very costly for auditing firms in the future. They might lose an edge over the larger auditing firms where knowledge is stored in the form of procedures, patents, and the like (Thorpe et al, 2005), which gives them a competitive advantage. The positive outcome of this study shows that auditors realize the importance of knowledge management and this will definitely create a new opportunity for auditing firms to develop their own knowledge management system in order to be competitive in the long run.

\section{References}

Alavi, M. and D. E. Leidner (2001). "Knowledge Management and Knowledge Management Systems: Conceptual Foundations and Research Issues." MIS Quarterly (25;1), 107-136.

Chang. K. L. et al (2005). KMPI: measuring knowledge management performance. Information and Management. (42), pp. 469-482.

Conner, K. R. and C. K. Prahalad (1996). "A resource-based theory of the firm: knowledge versus opportunism. Organization Science, (7;5): 477-501.

Darroch, J. and Mac Naughton, R. (2002). Examining the link between knowledge management practices and types of innovation. Journal of Intellectual Capital. (3;3). pp $210-222$.

Darroch, J. and Mac Naughton, R. (2002). Examining the link between knowledge management practices and types of innovation. Journal of Intellectual Capital. (3;3). pp 210-222.

Davenport, T. H. and L. Prusak (2000). Working Knowledge: How organizations manage what they know. Boston, Harvard Business School Press.

Davenport, T.H and Prusak,L. (1998). Working Knowledge: How Organizations Manage 
What They Know. Cambridge, MA: Harvard Business School Press.

De Tienne, K.B. et al (2004). Towards model of effective knowledge management and direction for future research: Culture, Leaderships, CKOs. Journal of Leadership and Organizational Studies. (10;4). pp. 27-43.

Desouza, K.C and Awazu, Y. (2006). Knowledge Management at SMEs: five peculiarities. Journal of Knowledge Management. (10;1). pp.32-43.

Du, Rong et al. (2007). Relationship between knowledge sharing and performance: A survey in Xian, China. Expert Systems with Applications. (32). pp. 38-46.

Dunfort, Richard (2000). Key challenges in the search for the effective management of knowledge in management in consulting firms. Journal of Knowledge Management. (4;4). pp 295-302.

Egbu C.O. et al. 2005. "Knowledge management for sustainable competitiveness in small and medium surveying practices". Structural Survey. (23,1), pp 7-21.

Gamble, P.R. and Blackwell, J. (2001). Knowledge Management: A state of the art guide. Kogen Page. London, UK.

Gold H.A. et al (2001). Knowledge management: An Organizational Capabilities Perspective. Journal of Management Information Systems. 18(1). pp 185-214

Gupta, B. et al (2000). Knowledge management: practices and challenges. Industrial Management and Data Systems. (100,1). pp 17-21.

Hansen, M.T., Nohria, N., Tierney, T., (1999). What's Your Strategy For Managing Knowledge? Harvard Business Review, March-April. pp. 106-116.

Hoffman. J.J. et al (2005). Social capital, knowledge management and sustained superior performance. Journal of Knowledge Management. 9(3). pp 93-100.

Lee, H. and Choi, B. (2003). Knowledge Management Enablers, Processes, and Organizational Performance: An Integrative View and Empirical Examination. Journal of Management Information Systems. (20,1). pp. 179-228

Lee. L.S. and Sukoco. B.M. (2007). The effects of entrepreneurial orientation and knowledge management capability on organizational effectiveness in Taiwan: The moderating role of social capital. International Journal of Management. (24,3). pp 549-572.

Levin. D.Z. and Cross, R. (2004). The strength of weak ties you can trust: the mediating role of trust in effective knowledge transfer. Management science. $(50,11)$. pp 1477-1490.

Nahapiet, J. and Ghosal, S. (1998). Social capital, intellectual capital, and the organizational advantage. Academy of Management Review. (23,2). pp. 242-266.

Nonaka, I. and Takeuchi, H. (1995). The knowledge-creating company: How Japanese Companies Create the Dynamics of Innovation. Oxford University Press. New York, NY. 
Nonaka, I. (1991). The knowledge-creating company. Boston, Harvard Business School Press.

Nooteboom, B. (1993). "Innovation and Diffusion in Small Firms: Theory and Evidence. Small Business Economics, (6). pp. 327-347.

Nunes. M.B. et al (2006). Knowledge management issues in knowledge-intensive SMEs. Journal of Documentation. (62,1). pp 101-119.

Nunnaly, J. (1978). Psychometric Theory. $2^{\text {nd }}$ Edition. McGraw Hill. New York.

Politis. J.D. (2003). The connection between trust and knowledge management: What are the implications for team performance. Journal of Knowledge Management. (7,5). pp 55-66.

Stewart, T. A. (2000). Intellectual Capital: The new wealth of organizations. London, Nicholas Brealey Publishing

Tat, L.W and Hase, S. (2007). "Knowledge management in the Malaysian aerospace industry". Journal of Knowledge Management, (11,1), pp 143-151.

Taylor, W.D. et al (2001). Managing knowledge-workers in accounting firms: the role of nutrient information and organizational information consciousness. Journal of Knowledge Management Practice, July 2001.

Thorpe. R. et al (2005). Using Knowledge Within Small and Medium-Sized Firms: A Systematic Review Of The Evidence. International Journal of Management Review. (7,4). pp. 257-281.

Widen-Wulff, G. and Suomi, R. (2007). Utilization of Information Resources for Business Success: The Knowledge Sharing Model. Information Resources Management Journal. $(20,1)$. pp 46-67

Yli-Renko, H., E. Autio, et al. (2001). "Social Capital, knowledge acquisition and knowledge exploitation in young technology-based firms." Strategic Management_Journal (22). pp. 587-613

Zander, U. and B. Kogut (1995). "Knowledge and the speed of the transfer and imitation of organizational capabilities: An empirical test." Organization Science, (6,1): 76-92. 